\title{
PROGRAMA EDUCATIVO EM MEDIDAS DE PRECAUÇÃO UNIVERSAIS: UMA METODOLOGIA DE ABORDAGEM
}

\author{
Maria Helena Baena de Moraes Lopes* \\ Meire Celeste Cardoso del Monte ** \\ Margarida Barbosa *** \\ Silzeth Schlichting Moromizato **** \\ Armanda Lúcia Nardi Fayan ***** \\ Edinaura Pereira de Souza***** \\ Edineide Oliveira de Melo***** \\ Ieda Rodrigues Lopes***** \\ Maria Clara Estanislau do Amaral ****** \\ Maria José Reis****** \\ Maria Sílvia T. Giacomasso Vergílio ******* \\ Marisa Visentin Garcia****** \\ Regina Célia Tazinazzo***** \\ Sônia Aparecida Fâncio***** \\ Teresa Celina Meloni Rosa*******
}

LOPES, M.H.B. de M. et al. Programa educativo em medidas de precaução universais: uma metodologia de abordagem.

Rev.latino-am.enfermagem, Ribeirão Preto, v. 5, n. 2, p. 83-91, abril 1997.

No Centro de Atenção Integral à Saúde da Mulher (CAISM) desenvolveu-se um programa de reciclagem sobre as Medidas de Precaução Universais (MPU) e divulgou-se, através de uma cartilha, essas medidas e os procedimentos em caso de acidente de trabalho. Primeiramente, o funcionário era sensibilizado para a questão do estresse e sua influência sobre a qualidade de vida e, após, era realizada a reciclagem promovendo-se a reflexão sobre as conseqüências da não adoção das MPU. Foram respondidos e analisados 286 pré-testes e 242 pós-testes com um índice de acertos significativamente maior nestes últimos ( $p<0,01)$, principalmente quanto ao uso adequado de luvas.

UNITERMOS: equipamentos de proteção, educação contínua em enfermagem, prevenção de acidentes

\section{INTRODUÇÃO}

Em 1987, o Centro de Controle de Doenças (Centers For Disease Control - CDC) - EUA, publicou uma série de recomendações destinadas aos profissionais de saúde, denominadas precauções universais ${ }^{1,2}$, com a finalidade de diminuir o risco de infecção por HIV (Human Imunodeficiency Virus) e HBV (Hepatitis B Virus ) no contato com sangue e fluidos corporais.

$\mathrm{O}$ risco de transmissão de agentes patógenos veiculados pelo sangue, tais como o HIV ou o HBV, depende da duração e freqüência da exposição do profissional ao sangue de pacientes infectados ${ }^{6}$. O risco de exposição é influenciado por fatores ambientais, tais como um contato maior com agulhas ou instrumentos contaminados, disponibilidade de equipamento de proteção efetivo e soro-prevalência do HIV e HBV na população.

O CAISM (Centro de Atenção Integral à Saúde da Mulher) é um hospital com 150 leitos, voltado ao atendimento da mulher, com unidades de Ginecologia, Obstetrícia, Oncologia-Ginecológica e Mamária e

\footnotetext{
* Professora Assistente Doutora do Departamento de Enfermagem da Faculdade de Ciências Médicas (FCM) e Coordenadora do Programa de Educação Continuada do CAISM - Universidade Estadual de Campinas - UNICAMP

** Enfermeira do CCIH do CAISM - UNICAMP

*** Enfermeira do Programa de Educação Continuada do CAISM - UNICAMP

**** Aluna do Curso de Enfermagem da UNICAMP

***** Enfermeira de Serviço de Enfermagem do CAISM - UNICAMP

****** Supervisora de Serviço de Enfermagem do CAISM - UNICAMP

******* Diretora de Serviço de Enfermagem do CAISM - UNICAMP
} 
Berçário de Alto Risco. Um local como o CAISM possui condições e desenvolve práticas que podem aumentar a duração e a frequiência da exposição do profissional ao sangue, uma vez que o principal tipo de atendimento está relacionado a procedimentos ginecológicos e obstétricos. Agrava essa situação o fato de que se tem observado um aumento significativo de mulheres com AIDS (Síndrome da Imunodeficiência Adquirida). No estado de São Paulo, até 31 de julho de 1993, havia 4.157 casos em mulheres e 22.182 em homens, com uma relação homem:mulher de 4:1, sendo que, em 1985, esta relação era de 42:1 ${ }^{7}$.

O conceito de Medidas de Precaução Universais (MPU) pressupõe que todos os pacientes estão potencialmente infectados com agentes patógenos transmitidos pelo sangue. Por esta razão, os profissionais de saúde devem utilizar cuidados de barreira, sempre que houver possibilidade de contato com sangue ou fluidos corporais. Sabe-se que esses procedimentos implicam em alocação de recursos, tanto para serem implementados quanto para serem mantidos. Por outro lado,as Precauções Universais efetivamente reduzem (mas não eliminam) o risco de exposição ocupacional.

Em 1989, o CAISM recebeu as primeiras mulheres soropositivas para o HIV. Este fato gerou muita ansiedade entre os funcionários do Hospital, principalmente em virtude da falta de informação. Em conseqüência, e tendo-se em vista as recomendações do CDC, as enfermeiras da CCIH (Comissão de Controle de Infecção Hospitalar) e do Serviço de Educação em Saúde efetuaram um treinamento visando a divulgação dos conceitos gerais sobre a AIDS e as MPU, destinado a todos os funcionários do Hospital (Enfermagem, Limpeza e Serviço Administrativo).

O programa de treinamento constituía-se de reuniões de aproximadamente uma hora e meia, com discussão e esclarecimento de dúvidas, após a exposição dos temas. Foram utilizados recursos audiovisuais como "slides" e fitas-cassete e elaborados cartazes, contendo as principais MPU, que permaneceram afixados em todos os setores cerca de dois anos.

Em 1993, após quase quatro anos deste treinamento inicial, verificou-se que havia necessidade de uma reciclagem das MPU para os funcionários da Divisão de Enfermagem. Considerando-se que não só a eficácia dessas medidas deveriam ser periodicamente avaliadas e aprimoradas, mas sobretudo o uso adequado das MPU (e.g. uso de luvas de acordo com o procedimento) e a adesão dos profissionais a essas normas, foi proposto: verificar o conhecimento prévio dos funcionários quanto às MPU; verificar as propostas apresentadas por eles para promover a adoção de MPU e investigar o conhecimento posterior dos mesmos após o desenvolvimento do programa educativo.

\section{MÉTODOS}

\section{Programa educativo e metodologia utilizada}

Para o desenvolvimento deste programa, que deveria conter aspectos relacionados à reciclagem em MPU, foi organizada uma comissão composta por representantes dos Serviços de Enfermagem, Programa de Educação Continuada e enfermeira da CCIH do CAISM. Esta comissão foi denominada Comissão de Precauções Universais.

As representantes dos Serviços de Enfermagem observaram, durante uma semana, o setor em que atuavam, verificando se as MPU eram ou não adotadas. Caso constatassem que dado funcionário não estava fazendo uso das medidas, questionavam-no se conhecia as MPU que deveriam ser empregadas naquela situação e, em caso de resposta afirmativa, o porquê da não adoção.

Verificou-se que os funcionários sabiam da necessidade das MPU, mas justificavam sua não adoção pelo fato de serem "cuidadosos" ou por não terem a mão o material apropriado (e. g. luvas e recipiente para desprezar materiais pérfuro-cortantes). Constatou-se também que muitos setores faziam uso inadequado das luvas, desconhecendo que havia diferentes tipos disponíveis e que as luvas cirúrgicas, por exemplo, somente deveriam ser utilizadas em procedimentos pertinentes. Em razão disto, o programa educativo passou a enfatizar a adequação do uso de luvas para cada situação.

A Comissão de Precauções Universais discutiu exaustivamente essas questões e concluiu que a metodologia de abordagem das medidas de precauções universais nas atividades de treinamento deveria ser modificada, uma vez que não estava promovendo a adesão a estas medidas.

Segundo FREIRE", "não é possível fazer uma reflexão sobre o que é a educação sem refletir sobre o próprio homem". Ainda segundo esse autor, a educação é uma busca realizada por um sujeito que é o homem, portanto, ele não deve ser objeto dela. Por isso, "ninguém educa ninguém". Ele acrescenta ainda, que essa busca não deve ser solitária, uma vez que "o homem não é uma ilha"e há uma relação estreita entre "comunhão e busca".

Para $\mathrm{DEMO}^{3}$, a participação é o "cerne da educação" e esta deve ser entendida como processo formativo e não apenas informativo.

Em vista disso, a Comissão optou pela utilização de uma metodologia de abordagem onde o tema, as MPU, fosse abordado dentro de um processo participativo e de reflexão, acreditando que o processo de ensinoaprendizagem deve objetivar a mudança do senso comum para a consciência crítica. Segundo Silva et al. ${ }^{8}$ essa idéia é contemplada na teoria educacional crítica. 
Elaborou-se um programa educativo onde constaram dois momentos: primeiramente o funcionário era sensibilizado para a questão do estresse e sua influência sobre a qualidade de vida, com enfoque na importância da auto-estima e do autocuidado. Essa atividade foi desenvolvida na forma de um seminário com duração de três horas e meia realizado pela Diretoria Geral de Recursos Humanos (DGRH) da Universidade Estadual de Campinas (UNICAMP). Esta primeira fase tinha como objetivo promover a reflexão e conscientizar o funcionário de que as MPU visavam a sua própria segurança.

Numa segunda etapa, uma semana após o seminário, foi realizada a reciclagem sobre as MPU. Esta atividade durou aproximadamente três horas e quarenta e cinco minutos. Foi elaborado um cronograma onde foram agendadas todas as sessões de reciclagem e escalados os membros da Comissão, responsáveis por cada sessão (um coordenador, um expositor e um secretário). Com a finalidade de capacitar os integrantes da Comissão efetuava-se um rodízio a cada duas sessões, de forma que, à saída de um membro correspondia a entrada de outro ainda sem participação, até que toda a Comissão se tornasse apta a realizar esta atividade.

Durante a sessão de reciclagem efetuaram-se:

1. Entrega de crachás: o primeiro nome, escrito de forma visível para que todos pudessem ser facilmente identificados pelo grupo.

2. Pré-teste: distribuíu-se um questionário com um total de 8 questões (Anexo 1) para avaliar o conhecimento prévio do funcionário.

3. Discussão do conceito de MPU: o grupo discutiu e elaborou um conceito de MPU que foi anotado em quadro negro ou álbum seriado.

4. Apresentação das MPU: foi apresentado um "kit"de 47 "slides" elaborados pela $\mathrm{CCIH}$, e outros relativos aos diferentes tipos de luvas (procedimento estéril, não estéril e cirúrgico). Distribuíram-se amostras de cada um dos tipos para que o grupo pudesse manuseá-las.

5. Apresentação de um caso hipotético: apresentouse o caso hipotético de um hospital onde, embora os funcionários tivessem recebido treinamento quanto às MPU e a administração houvesse providenciado material em qualidade e quantidade adequadas, o pessoal de enfermagem nem sempre observava as Medidas de Precaução Universais preconizadas. Em conseqüência, um auxiliar de enfermagem contraiu hepatite B, após exposição ocupacional, que evoluiu para a forma crônica e, um funcionário da Prefeitura feriu-se com uma lâmina de bisturi ao recolher o lixo deste mesmo hospital.

7. Reflexão: questionou-se por que as MPU nem sempre são adotadas, anotando-se as respostas numa lousa ou álbum seriado.

8. Propostas de solução: os participantes foram divididos, de forma aleatória, em três grupos denominados: "grupo A - Administração", "grupo B Divisão de Enfermagem" e "grupo C - Educação Continuada/ CCIH". Os grupos representavam, portanto, respectivamente, a Administração, a Divisão de Enfermagem e a Educação Continuada e CCIH do hospital hipotético. O objetivo desta atividade foi o de fazer com que os membros do grupo se sentissem coresponsáveis pela busca de propostas e estratégias que visassem maior adesão às MPU. As sugestões dos grupos foram anotadas, apresentadas e discutidas por todos os participantes, dispostos em círculo ou semi-círculo.

9. Reforço das informações (técnica do barbante): os participantes permaneciam dispostos em círculo. $\mathrm{O}$ coordenador, ao fazer uma pergunta, lançava uma bola de barbante, segurando-a pela ponta. A pessoa que pegasse a bola deveria responder à questão e, também prendendo o barbante, lançar a bola para outro integrante do grupo que, por sua vez, precisaria responder a nova pergunta feita pelo coordenador e, novamente, jogar a bola segurando o barbante, até que todos os participantes a tivessem recebido, formando-se, assim, uma "teia". O coordenador comentava então o significado da "teia": a não adoção das MPU era um problema de difícil solução, causado por todos e que dependia da totalidade dos integrantes para que fosse resolvido. A seguir, cada pessoa devolvia a bola para o seu parceiro e formulava, numa frase, o que para ela significavam as MPU, desfazendo-se, assim, a "teia".

10. Entrega de "buttons" e cartilhas: ao término da atividade, cada pessoa recebia uma cartilha com as MPU e sobre como proceder em caso de acidente de trabalho, além de um "button" que o identificava como um "VIGILANTE DAS MEDIDAS DE PRECAUÇÃO UNIVERSAIS" (Figura 1), reforçando, desta forma, o compromisso de cuidar, zelar e adotar medidas de segurança para consigo e os outros. Recomendava-se que o significado não fosse revelado a quem não houvesse assistido a reciclagem para estimular a participação dos demais.

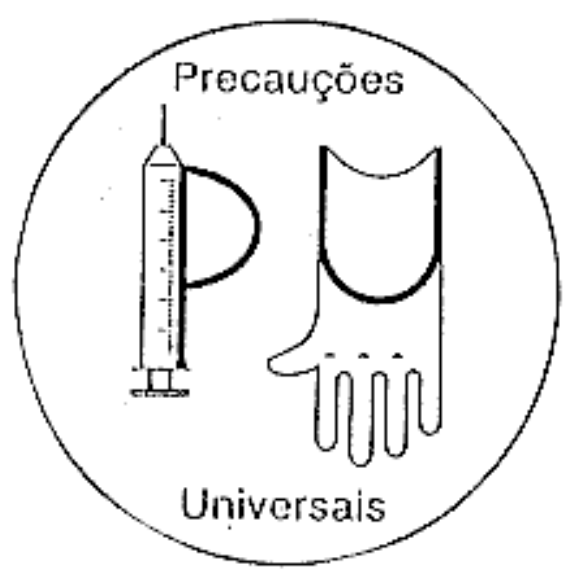

Figura 1. "Button" de "VIGILANTE DAS MEDIDAS DE PRECAUÇÃO UNIVERSAIS” 
2. Avaliação da aprendizagem

Aplicou-se um pós-teste, contendo as mesmas questões do pré-teste, três a quatro meses após a reciclagem. Os questionários não respondidos foram enviados uma segunda vez, em agosto de 1994.

Cada questão foi avaliada segundo seu índice de acerto ou "nota" que variou de zero a um. Foi feita a comparação das "notas" de cada questão, de forma não pareada, entre os questionários do pré e pós-teste, utilizando-se o teste não paramétrico de KRUSKALWALLIS ${ }^{9}$, com nível de significância de $5 \%$.

\section{RESULTADOS E DISCUSSÃO}

Um total de 286 funcionários da Divisão de Enfermagem do CAISM submeteram-se ao programa educativo proposto, no período de agosto de 1993 a julho de 1994. Em agosto de 1993, a Divisão de Enfermagem contava com 428 funcionários e, em julho de 1994, com 422. Os funcionários contratados neste período receberam orientações sobre as MPU durante o treinamento de admissão e, portanto, não fizeram parte da população alvo.

Foram realizados dezoito seminários relacionados a estresse e qualidade de vida e vinte e quatro reciclagens sobre as MPU.

Quanto ao conhecimento prévio apresentado por estes funcionários, os resultados encontram-se na Tabela 1.

Tabela 1. Índice de acertos das questões do préteste $(\mathbf{n = 2 8 6})$

\begin{tabular}{ccc}
\hline QUESTÃO & MÉDIA & DESVIO PADRÃO \\
\hline Questão 1 & 0,70 & $\pm 0,13$ \\
Questão 2 & 0,68 & $\pm 0,47$ \\
Questão 3 & 0,57 & $\pm 0,25$ \\
Questão 4 & 0,61 & $\pm 0,23$ \\
Questão 5 & 0,64 & $\pm 0,19$ \\
Questão 6 & 0,80 & $\pm 0,17$ \\
Questão 8 & 0,24 & $\pm 0,29$ \\
\hline
\end{tabular}

Foram aplicados 286 pré-testes, aos quais responderam 66 enfermeiros, 20 técnicos, 72 auxiliares e 116 atendentes de enfermagem (12 funcionários não identificaram sua categoria profissional).

Os resultados obtidos demonstraram que embora os funcionários, em virtude de treinamentos anteriores, tivessem conhecimentos sobre as MPU, o conceito das mesmas não era claro (questão 8). Havia dúvidas quanto a algumas medidas e muitos não sabiam qual a luva mais adequada para determinados procedimentos (questão 4).

Quanto aos resultados da reflexão sobre o caso hipotético, a Tabela 2 mostra as sugestões apresentadas pelos funcionários que participaram do "grupo $\boldsymbol{A}$ Administração" (vide conformação dos grupos na descrição dos métodos). As medidas educativas (treinamento, conscientização, divulgação de acidentes e supervisão) tiveram maior frequiência $(\mathbf{6 6 , 3 \%})$. As medidas punitivas (advertência verbal, desconto de um dia de trabalho, suspensão e outras) também foram freqüentemente citadas $(\mathbf{1 6 , 2 \%})$. Outras propostas apresentadas por este grupo foram: provimento de recursos materiais em quantidade e qualidade adequadas, avaliação (reuniões periódicas para a discussão das dificuldades, análise de falhas e dos treinamentos sobre Precauções Universais, condições de trabalho e outras) e medidas de incentivo (elogios, premiação, pontuação maior no julgamento do desempenho e outras).

Tabela 2. Propostas apresentadas pelo grupo A (Administração) para promover a adoção das MPU

\begin{tabular}{lcc}
\hline \multicolumn{1}{c}{ PROPOSTAS } & n & $\mathbf{\%}$ \\
\hline $\begin{array}{l}\text { Treinamento/Reciclagem/Campanhas } \\
\text { Medidas de conscientização (reuniões, }\end{array}$ & 18 & 22,5 \\
cartazes) & 16 & 20,0 \\
$\begin{array}{l}\text { Divulgação/Notificação de acidentes } \\
\text { com pérfuro-cortantes }\end{array}$ & 14 & 17,5 \\
Medidas punitivas & 13 & 16,2 \\
Provimento de recursos materiais em & & \\
qualidade e quantidade adequadas & 6 & 7,5 \\
Avaliação (identificação de falhas) & 6 & 7,5 \\
Supervisão da adoção das MPU & 5 & 6,3 \\
Medidas de incentivo & 2 & 2,5 \\
TOTAL & $\mathbf{8 0}$ & $\mathbf{1 0 0 , 0}$ \\
\hline
\end{tabular}

Na Tabela 3 são apresentadas as sugestões dos funcionários que participaram do "grupo B - Divisãa de Enfermagem". Também nesse grupo as medidas educativas apareceram com maior freqüência $(\mathbf{6 0 , 8 \%})$, seguidas pelas medidas punitivas $(\mathbf{1 5 , 9 \% )}$. No item "outros" foram agrupadas as propostas que apareciam uma única vez, como por exemplo, aumento do número de funcionários, apoio terapêutico aqueles que se mostraram resistentes ao uso das MPU e outras. 
Tabela 3. Sugestões apresentadas pelo grupo B (Divisão de Enfermagem) para promover a adoção das MPU

\begin{tabular}{lcc}
\hline \multicolumn{1}{c}{ PROPOSTAS } & n & $\mathbf{\%}$ \\
\hline Treinamento/Reciclagem/Campanhas & 25 & 23,4 \\
Medidas punitivas & 17 & 15,9 \\
Supervisão da adoção das MPU & 17 & 15,9 \\
Medidas de conscientização (reuniões, & 15 & 14,0 \\
cartazes) & & \\
Avaliação (identificação de falhas) & 13 & 12,0 \\
Divulgação/Notificação de acidentes & 8 & 7,5 \\
com pérfuro-cortantes & & \\
$\begin{array}{l}\text { Provimento de recursos materiais em } \\
\text { qualidade e quantidade adequadas }\end{array}$ & 5 & 4,7 \\
$\begin{array}{l}\text { Medidas de incentivo } \\
\text { Outros }\end{array}$ & 5 & 4,7 \\
ToTAL & 2 & 1,9 \\
\end{tabular}

As propostas do "grupo $\boldsymbol{C}$ - Educação Continuada/CCIH" são apresentadas na Tabela 4. As medidas educativas também englobam a grande maioria das sugestões deste grupo $\mathbf{( 7 4 , 2 \% )}$.

Tabela 4. Propostas para a adoção das MPU apresentadas pelo grupo C (Educação Continuada/ CCIH)

\begin{tabular}{lcc}
\hline \multicolumn{1}{c}{ PROPOSTAS } & n & $\mathbf{\%}$ \\
\hline Treinamento/Reciclagem/Campanhas & 30 & 32,3 \\
Medidas de conscientização (reuniões, & 23 & 24,7 \\
cartazes) & & \\
Supervisão da adoção das MPU & 14 & 15,0 \\
Avaliação (identificação de falhas) & 9 & 9,7 \\
Outros & 7 & 7,5 \\
Medidas punitivas & 4 & 4,3 \\
Medidas de incentivo & 4 & 4,3 \\
Divulgação/Notificação de acidentes & 2 & 2,2 \\
com pérfuro-cortantes & & \\
TOTAL & $\mathbf{9 3}$ & $\mathbf{1 0 0 , 0}$ \\
\hline
\end{tabular}

No que se refere ao conhecimento posterior destes funcionários, após o desenvolvimento do programa educativo, os resultados encontram-se a seguir (Tabela $5)$.
Tabela 5. Índice de acertos das questões do pósteste $(n=242)$

\begin{tabular}{lcc}
\hline QUESTÃO & MÉDIA & DESVIO PADRÃO \\
\hline Questão1 & 0,77 & $\pm 0,11$ \\
Questão 2 & 0,74 & $\pm 0,44$ \\
Questão 3 & 0,74 & $\pm 0,20$ \\
Questão 4 & 0,72 & $\pm 0,19$ \\
Questão 5 & 0,68 & $\pm 0,15$ \\
Questão 6 & 0,86 & $\pm 0,13$ \\
Questão 8 & 0,28 & $\pm 0,32$ \\
\hline
\end{tabular}

Responderam ao pós-teste um total de 242 funcionários, sendo: 36 enfermeiros, 15 técnicos, 51 auxiliares e 90 atendentes de enfermagem (50 funcionários não identificaram sua categoria profissional).

Comparando-se as "notas" das questões dos pré e pós-testes pelo teste de Kruskal-Wallis, com exceção das questões 2 e 8 , as demais diferiram significativamente ( $p<0,01$ ), sendo mais elevadas no pós -teste.

Com a reciclagem, muitas questões foram sanadas, conforme demonstram os resultados dos póstestes. O conceito de MPU permaneceu mal definido para a maioria dos funcionários (questão 8) e uma possível explicação para esse achado é que os funcionários com menor nível de escolaridade (atendentes de enfermagem) tiveram dificuldade em expressar-se porque tiveram que fazê-lo por escrito. A evidência disso é que, durante a reciclagem, os grupos construíram corretamente o conceito.

\section{CONSIDERAÇÕES FINAIS}

A participação nas atividades foi voluntária e embora tenha sido incentivada e facilitada, cerca de $30 \%$ dos funcionários não fizeram a reciclagem. Durante as sessões relativas ao caso hipotético de não observação das MPU, todos os grupos de discussão apresentaram, com frequiência, propostas educativas, expressando, também, a necessidade de adoção de normas punitivas em certos casos. Tornou-se evidente, nas discussões, que os funcionários identificaram o uso das MPU como um ato de responsabilidade não só para consigo mesmos mas também para com o outro e que os treinamentos e reciclagens são necessários.

Durante as sessões de reciclagem, constantes no programa educativo, procurou-se enfatizar a auto-estima e o autocuidado como fatores relevantes para a adesão às MPU.

Pretendemos numa segunda etapa avaliar, através 
da observação direta nos setores, a adesão às MPU. Temos por objetivo, também, desenvolver material educativo e cartazes, conforme sugestões dos funcionários.

Mensalmente divulgamos os acidentes com pérfuro-cortantes, porém, ainda não iniciamos um trabalho educativo com estes funcionários.

Estudos realizados em outros países demonstraram que alunos de Medicina, ao se graduarem, não possuem conhecimento adequado das MPU ${ }^{5}$.É provável que o mesmo ocorra em nosso meio, não só em relação aos médicos mas também entre os profissionais de enfermagem em geral. Assim, faz-se necessário o desenvolvimento de programas de educação continuada nos Serviços de Saúde, envolvendo todos os profissionais da área, para treinamento e reciclagem.

Sabemos que o treinamento é um processo contínuo, assim, não podemos considerar nosso trabalho concluído. Contudo, a experiência foi bastante positiva, envolvendo um grande grupo de representantes dos diferentes Serviços de Enfermagem, com participação ativa em todas as fases, desde o planejamento até a avaliação das atividades.

\section{UPDATING MEASURES ON UNIVERSAL PRECAUTIONS: A NEW APPROACH METHODOLOGY}

An updating program on measures of universal precautions (M.U.P.) was developed at the Center of Whole Care of Woman's Health (Centro de Atenção Integral à Saúde da Mulher-CAISM). These measures and the procedures in the case of work accident were published in a booklet. First, servants should be aware of the matter of stress and its influence on the quality of life. Then, updating was carried through encouraging the reflection on the consequences of the non-adoption of M.U.P. The answers to 286 pre-tests and 242 post-tests were analyzed and the results showed a significantly higher index of correct answers $(p<0,01)$, mainly regarding the appropriate use of glove.

KEY WORDS: protective devices, nursing continuing education, accident prevention

\section{ABORDAJE DE UNA NUEVA METODOLOGIA: RECICLAJE DE MEDIDAS DE PRECAUCIÓN UNIVERSALES}

El Centro de Atención Integral a la Salud de la Mujer (CAISM) desarrolló un programa de reciclaje sobre Medidas de Precaución Universales (MPU). Se divulgó por medio de un material educativo (cartilla) las MPU y procedimientos en caso de accidentes de trabajo. En primer lugar se cuestionó al funcionário sobre el stress y su influencia en la calidad de vida, llevando se a cabo el reciclaje en el cual se promovió la reflexión sobre consecuencias cuando las MPU no son adoptadas. Fueron respondidas y analizadas 286 pre-test y 242 pos-test con un índice de acierto significativamente mayor en este último (p <0,01), principalmente con relación al uso adecuado de los guantes.

TÉRMINOS CLAVES: equipos de protección, educación contínua de enfermería, prevención de accidentes

\section{REFERÊNCIAS BIBLIOGRÁFICAS}

01. CENTERS FOR DISEASE CONTROL. Recommendations for prevention of HIV transmission in health-care settings. MMWR, v. 36, n. 2s, p. 3-17, 1987.

02. CENTERS FOR DISEASE CONTROL. Update: universal precautions for prevention of transmission of human imunodeficiency virus, hepatitis B virus, and other bloodborne pathogens in health-care setting. MMWR, v. 37, p. 378388, 1988.

03. DEMO, P. Avaliação qualitativa. 3. ed. São Paulo: Cortez, 1991. 104 p.

04. FREIRE, P. Educação e mudança. 15. ed. Rio de Janeiro: Paz e Terra, 1979. 80 p.

05. KOENIG, S.; CHU, J. Senior medical student's knowledge of universal precautions. Acad. Med., v. 68, n. 5, p. 372-374, May 1993.
06. McKINNEY, W. P.; YOUNG, M. J. The cumulative probability of occupationally-acquired HIV infection: the risks of repeated exposures during a surgical career. Infect. Control. Hosp. Epidemiol., v. 11, p. 243-247, 1990.

07. SÃO PAULO. Secretaria de Estado da Saúde. Revista de Informações Interdisciplinares em AIDS,. v. 2, n. 1, jan/fev/mar.,1994.

08. SILVA, M. J. P. da; PEREIRA, L. L.; BENKO, M. A. Escolha de uma linha educacional. In: Educação continuada: estratégia para o desenvolvimento do pessoal de enfermagem. Rio de Janeiro: Marques-Saraiva; São Paulo: Editora da Universidade de São Paulo, 1989. Cap. 1, p.1-7.

09. SIEGEL, S. Non parametric statistics. 2. ed. New York: Mc Graw-Hill, 1972. 
ANEXO 1

Categoria: Atendente de Enfermagem ( ) Técnico de Enfermagem ( )
Auxiliar de Enfermagem ( )

Enfermeiro

Serviço de Enfermagem:

Horário de trabalho: das

às

Setor:

Data:

\section{Questionário sobre Precauções Universais com Sangue e Fluidos Corporais}

1. Assinale com um X os itens que você considera fazerem parte das Medidas de Precaução Universais:

( ) Lavagem das mãos

( ) Transporte de materiais orgânicos para exame (sangue, peças, etc...) em recipientes envoltos em plástico

( ) Uso de luvas, quando em contato com sangue, urina, fezes, secreções

( ) Uso de aventais impermeáveis, quando há risco de contaminação do tórax e abdome com sangue e fluidos corporais

( ) Uso de gorros e propés em área restrita

( ) Descarte de materiais cortantes e agulhas em recipiente rígido e identificado

( ) Não reencape de agulhas

( ) Uso de máscaras e óculos de proteção, quando há risco de contaminação da mucosa oral e ocular com sangue e fluidos corporais

( ) Escovação de mãos e braços antes de atos cirúrgicos

( ) Uso de antibióticos, em pacientes, antes do início da cirurgia

( ) Pré-desinfecção de instrumental cirúrgico

2. As Precauções Universais devem ser adotadas: (Assinale uma alternativa)

( ) Quando cuidamos de pacientes soro-positivos para HIV e daqueles portadores de hepatite

( ) Para cuidar de pacientes com comportamento de risco de adquirir HIV

( ) Para cuidar de qualquer paciente com doença contagiosa (viral ou bacteriana)

( ) Para cuidar de qualquer paciente, quando envolvidas manipulação de sangue e fluidos corporais

3. Assinale F (Falso) ou V (Verdadeiro) ao lado de cada afirmação:

( ) Devemos usar luvas de procedimento, sempre que entrarmos em contato com a pele do paciente, mesmo íntegra

( ) As luvas estéreis protegem melhor o funcionário que as não-estéreis

( ) Não devemos desconectar a agulha da seringa ao desprezá-las nos coletores de pérfuro-cortantes

( ) O uso de luvas substitui a lavagem das mãos antes e após o procedimento

( ) Não é preciso usar luvas para prestar cuidados de higiene às crianças e recém-nascidos em geral

4. Qual a luva mais indicada para cada ocasião? (Assinale com um X na coluna correspondente)

\section{Procedimento}
a) curativo simples com uso de pinças
b) cateterismo vesical
c) limpeza de unidade
d) aspiração traqueal
e) punção de veia

$\begin{array}{cc}\frac{\text { Luva de proced. }}{\frac{\text { estéril }}{()}} & \frac{\text { Luva de proced. }}{\text { não-estéril }} \\ () & () \\ () & () \\ () & ()\end{array}$

Luva
cirúrgica
$(3)$
$(3)$
()

Nehuma $\underline{\text { luva }}$ 
5. Assinale com um $X$ quais as precauções de barreira que devemos adotar em cada um dos procedimentos abaixo: (Assinale com um $\mathrm{X}$ uma ou mais colunas)

\section{Procedimento}

a) troca de forro sujo de sangue

b) banho no leito

c) coleta de sangue com "Vacutainer"

d) sinais vitais em pacientes soro-positivos para HIV

e) esvaziamento do coletor de diurese

f) cuidados a pacientes com vômitos e diarréia em jato

g) extração manual de leite

h) instrumentação de cirurgia

i) colocação e retirada de comadre

j) lavagem de instrumental

k) instalação de venóclise

1) esvaziamento de "Portovac"

m) coleta de PKU nos recém-nascidos ("teste do pezinho")

Luva
()
()
()
()
()
()
()
()
()
()

\section{Máscaras é́culos}

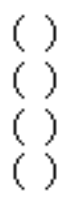

()

$\stackrel{\text { Avental }}{\text { impermeável }} \quad \frac{\text { Nenhuma }}{\text { precaução }}$

6. Se você sofresse um acidente com agulha contaminada ou lâmina de bisturi, o que você faria? (Assinalar as alternativas que você achar corretas)

( ) Lavaria as mãos

( ) Espremeria o ferimento para retirar sangue

( ) Iria ao Centro de Saúde da Comunidade (CECOM)

( ) Desinfetaria o local com PVPI tintura ou álcool a 70\%

( ) Desinfetaria o local com hipoclorito

( ) Comunicaria o ocorrido à Associação dos Servidores da UNICAMP (ASSUC), por ser acidente de trabalho

( ) Não me incomodaria com o fato

7. Que razões levam você a nem sempre adotar as Medidas de Precaução Universais no dia a dia?

( ) Falta de luvas disponíveis no momento em que preciso

( ) Falta de desinfetantes e antissépticos no setor

( ) Não recebi orientação quanto às Medidas de Precaução Universais

( ) Não me lembro das Medidas que devo usar em cada caso

( ) As luvas disponíveis não são apropriadas

( ) Uso Medidas de Precaução somente em pacientes soro-positivos para HIV ou em casos suspeitos

( ) Preocupo-me com as precauções somente em pacientes com hepatite e doenças contagiosas

( ) Essas precauções são disponíveis, porque sou muito cuidadosa(o)

( ) Os pacientes, sob os meus cuidados, não estão contaminados

( ) Acho difícil usar luvas para puncionar veias

( ) Ninguém adota precauções no meu setor

( ) Ninguém me cobra ou orienta neste sentido

( ) Os pacientes se sentirão constrangidos se eu usar luvas para manipulá-los

( ) Uso, sempre, as Medidas de Precaução Universais

( ) Outras razões. Quais? 
